\title{
LM-01K005
}

\section{LDV Measurement of Confined Parallel Jet Mixing}

Robert F. Kunz, Stephen W.D'Amico, Peter F. Vassallo, Michael A. Zaccaria

This report was prepared as an account of work sponsored by the United States Government. Neither the United States, nor the United States Department of Energy, nor any of their employees, nor any of their contractors, subcontractors, or their employees, makes any warranty, express or implied, or assumes any legal liability or responsibility for the accuracy, completeness or usefulness of any information, apparatus, product or process disclosed, or represents that its use would not infringe privately owned rights. 


\title{
LDV Measurement of Confined Parallel Jet Mixing
}

\author{
Robert F. Kunz ${ }^{1}$, Stephen W. D'Amico, Peter F. Vassallo, Michael A. Zaccaria \\ Lockheed Martin \\ Schenectady, NY 12301
}

1. Corresponding Author, Current Address: Applied Research Laboratory, The Pennsylvania State University,

P.O. Box 30, University Park, PA 16804

\begin{abstract}
Laser Doppler Velocimetry (LDV) measurements were taken in a confinement, bounded by two parallel walls, into which issues a row of parallel jets. Two-component measurements were taken of two mean velocity components and three Reynolds stress components. As observed in isolated three dimensional wall bounded jets, the transverse diffusion of the jets is quite large. The data indicate that this rapid mixing process is due to strong secondary flows, transport of large inlet intensities and Reynolds stress anisotropy effects.
\end{abstract}

\section{Nomenclature \\ Symbols \\ $A_{x s}$ Cross sectional area of test section $\left(=7.74 \times 10^{-3} \mathrm{~m}^{2}\right)$} $A_{x s 1 / 4} \quad$ Area of $1 / 4$ jet cross section AR Nozzle aspect ratio (= nozzle height/nozzle width) h Confinement height $(=0.0195 \mathrm{~m})$ L Distance between adjacent jet centerlines $(=0.0762 \mathrm{~m})$ N Number of samples taken Q Volume flow rate through facility ( $=6.31 \times 10^{-3} \mathrm{~m}^{3} / \mathrm{s}$ ) $\mathrm{Q}_{1 / 4} \quad$ Volume flow rate through $1 / 4$ jet cross section $\operatorname{Re} \quad$ Reynolds number based on $\mathrm{h}$ and $\mathrm{U}_{\text {bulk }}$ $\operatorname{Re}^{*} \quad$ Reynolds number based on $h$ and $U_{\mathrm{cl}}$ $U, V, W \quad$ Mean cartesian velocity components $\mathrm{U}_{\text {bulk }}$ Bulk velocity in confinement $\left(=\mathrm{Q} / \mathrm{A}_{\mathrm{xs}}=0.815 \mathrm{~m} / \mathrm{s}\right)$ $U_{c 1}$ Mean velocity at confinement centerline $(z=0.0 \mathrm{~m})$ $u^{\prime}, v^{\prime}, w^{\prime} \quad$ Fluctuating cartesian velocity components $\mathrm{x}, \mathrm{y}, \mathrm{z} \quad$ Cartesian coordinates as defined in Figure 1

Subscripts cl jcl Midpoint between jets 2 \& $3(y=0.1651 \mathrm{~m} z=0.0 \mathrm{~m})$

\section{Introduction}

Three dimensional bounded jets are important in a variety of engineering applications including turbine blades, gas turbine combustors and microcircuit cooling, thrust vectoring nozzles, airfoil boundary layer control and ventilation system exhaust. Mixing of bounded jets with adjacent jets or with their surroundings (i.e. transverse and boundary normal momentum and heat transfer), plays a crucial role in the effectiveness of the injected flow in these applications. A considerable body of research has been performed which studies different classes of bounded jets. These include: jets bounded by free surfaces and solid walls, planar and threedimensional wall jets, jets bounded by one plane wall, two parallel plane walls and axisymmetric walls (pipe and diffuser geometries), and systems with multiple interacting jets of various configurations.

The authors investigated the mixing characteristics of parallel, confined turbulent jets. A large body of experimental research has been performed on related flows, which suggests that some of the physical mechanisms present in such Parallel, Confined Jets (hereafter PCJ) mixing are important in rapid transverse mixing in other bounded jet flows. Specifically, isolated three-dimensional wall bounded turbulent jets have been studied by numerous researchers. Measurements by Newman et al. [1972], and many others, on threedimensional isolated wall bounded jet flows have shown that transverse jet growth rates in these flows are substantially larger than the growth rates normal to the wall. Physical mechanisms to which this anisotropic jet growth have been attributed include increased turbulence transport (i.e. $\partial\left(u^{\prime} v^{\prime}\right) / \partial y>\partial\left(\overline{u^{\prime} w^{\prime}}\right) / \partial z$, see coordinate convention in Figure 1), and secondary flows of the first and second kind (Launder and Rodi [1983]). Also, Davis and Winarto [1980] took velocity and Reynolds stress measurements in an isolated three-dimensional wall bounded jet and observed larger effective momentum diffusion transverse to the jet than normal to the bounding wall.

An isolated three-dimensional wall jet bounded on two sides by a confinement has been studied by Holdeman and Foss [1975]. Their mean flow measurements showed strong secondary motions (streamwise vorticity) and large jet spreading tates.

Several nondimensional geometric scales can be adopted to characterize PCJ flows. The ratio of inlet nozzle hydraulic diameter to confinement height $\left(D_{H} / h\right)$ and to jet spacing $\left(D_{H} / L\right)$, as well as the nozzle aspect ratio (AR) are relevant and serve to distinguish the geometries investigated by others (see Figures 1 and 2). The configuration investigated in this report is characterized by closely confined, closely coupled and low aspect ratio jets (i.e. $D_{H} / h, D_{H} / L$ and $A R$ all of order 1 ).

PCJ configurations have been studied by Krothapalli et al. [1981]. They found that the spreading rates of a multiple rectangular jet configuration was not significantly affected by the presence of a partial confinement. However, the configuration considered in this report differs significantly from that of Krothapalli and his co-workers in that the aspect ratio of their tectangular jets was $A R \cong 20$ (vs. $\cong 1$ for the present geometry) and the normalized distance between their jets was $D_{H} / L \cong 5$ (vs. $\cong 1$ for the present geometry). Accordingly, the presence of a confinement in their experiments has significantly less influence on parallel jet mixing than observed in this study.

The purpose of the present PCJ measurement program was to take mean flow and Reynolds stress data of sufficient detail to improve the understanding of the physics in $\mathrm{PCJ}$ 
flows, develop an appropriate turbulence model and verify conputational fluid dynamics (CFD) analysis. An adequately verified CFD tool will provide the ability to optimize the flow rates and jet size/position to maximize mixing rates. The present experimental program contributes to the available measurements of bounded jet flows. The configuration investigated is characterized by the presence of multiple parallel jets, bounding surfaces on two sides, low aspect ratio jet cross-sections and close proximity of adjacent jet centerlines (relative to jet diameters). The purposes of this paper are to present and interpret the experimental measurements taken in the PCJ configuration.

\section{Configuration and Measurement Program}

Figures 1 and 2 show sketches of the test section and optical configuration used for the measurement program. The coordinate convention utilized throughout is also presented in Figure 1. Five pipes of diameter $D=0.0381 \mathrm{~m}$ and 22 diameters long issue into a confinement. The confinement is $0.01905 \mathrm{~m}$ in height, $0.4064 \mathrm{~m}$ wide and $0.7620 \mathrm{~m}$ long. The flat walls of the confinement give rise to very good optical access. The axis of the third pipe is coincident with the centerline of the confinement. The pipe centerlines are spaced $0.0762 \mathrm{~m}$ apart. The end walls $(\mathrm{y}=0.0$ and $0.4064 \mathrm{~m})$ were located $0.0508 \mathrm{~m}$ from the centerline of the outermost jets.

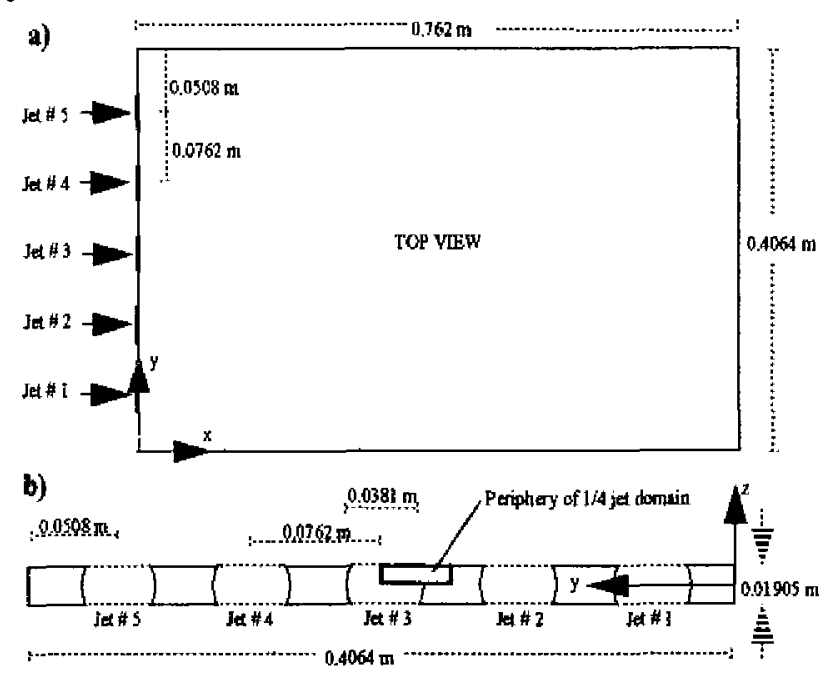

FRONT YTEW

Figure 1. a) Top view, b) Front view sketches of Parallel Confined Jet test section

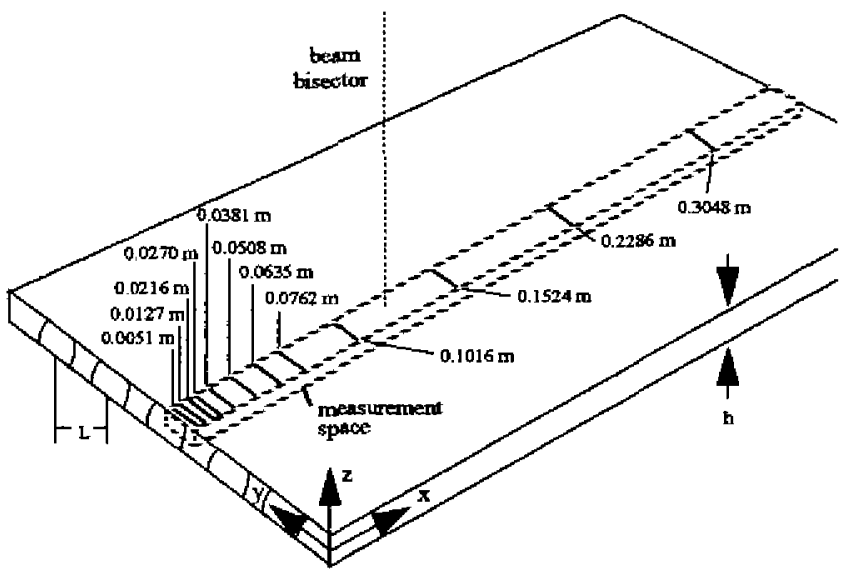

Figure 2. Sketch of probe orientation and 12 scan locations

The dynamics of the parallel confined jet flow can be qualitatively characterized as follows. As the water flowing through each of the five inlet pipes nears the inlet to the confinement, it accelerates because the cross-sectional areas at the inlet to the confinement are smaller than the pipe cross sectional area (Figure 1). As the jets issue into the confinement, they decelerate due to a step increase in flow area, and begin to diffuse in the transverse (y) direction. Recirculation zones appear between each pair of jets. The jets mix out quite rapidly - the centerline axial velocity of jet 3 , normalized by confinement bulk velocity, decreases from 2.7 to 1.6 $\mathrm{m} / \mathrm{s}$ within approximately 5 confinement heights downstream from the inlet. As the jets mix out, the region of the flow well away from the endwalls becomes a fully developed two-dimensional turbulent duct flow.

A $40 \mathrm{hp}$ variable speed centrifugal pump was used to control flow. The test section flow rate was measured to an accuracy of $\pm 1 / 2 \%$ of reading using a turbine flow meter in the supply line to the test section. Flow rates through the five inlet pipes were controlled and measured to an accuracy of $2.5 \times 10^{-5} \mathrm{~m}^{3} / \mathrm{s}$ using rotometers in the individual pipe inlet lines. The volume flow rate of water through the facility was $6.31 \times 10^{-3} \mathrm{~m}^{3} / \mathrm{s}$. The flow split was controlled via valves downstream from the rotometers. This flow split was optimized through trial and error to yield near periodicity of the three middle jets as discussed below. Loop temperature was controlled using resistance heaters located on the pump suction piping and chilled water through a heat exchanger as necessary. The loop temperature was held constant at $38^{\circ} \mathrm{C}$. The Reynolds number ( $\mathrm{Re}$ ) of the inlet pipe flows based on pipe bulk velocity and diameter was approximately 60000 .

The test section was designed using clear cast acrylic. To minimize distortion of the beams through the test section walls, the cast acrylic was milled to a $0.13 \mathrm{~mm}$ tolerance on thickness and polished to retain optical clarity.

A four-beam backscatter laser Doppler fiber optic velocimetry system was used to take the velocity measurements. A $122 \mathrm{~mm}$ focal length lens was utilized with the probe, producing a measurement volume $0.32 \mathrm{~mm}$ long and $0.06 \mathrm{~mm}$ wide in water. The fiberoptic probe was supported above the test section with a beam mounted to a milling machine which controlled traversing, with an estimated maximum positional error of $\pm 0.25 \mathrm{~mm}$. Neutrally buoyant latex seed particles $(5 \mathrm{\mu m})$ were used for the LDV measurements. Water added to the loop was deaerated to minimize the presence of bubbles in the flow stream. In all cases the 
beam powers were maintained between 30 and $60 \mathrm{~mW}$ for the green ( $514 \mathrm{~nm}$ wavelength) beams and between 10 and $20 \mathrm{~mW}$ for the blue ( $488 \mathrm{~mm}$ wavelength) beams. A 4 W Argon laser generated the beams.

A digital burst correlator was used to process the LDV data. This processor discriminates signal from noise using auto-correlation instead of amplifying deteetion. $A$ total of 256 digital samples per Doppler burst were analyzed to calculate a single velocity measurement. A $40 \mathrm{MHz}$ Brage shift was applied to one beam of each of the beam pairs to enable measuremeni of zero and negative velocities. Coincidence between the two velocity components was achieved by requiring that the two measurements be within a specified time interval. For this experiment, the coincidence interval specified was 100 us. The coincidence data rate varied between approximately $10 \mathrm{~Hz}$ and $300 \mathrm{~Hz}$, depending on the proximity of the measurement volume to the wall. Three thousand samples were taken at each point to maximize statistical certainty. A transit time wcighting scheme was used to correct the velocity data from biases due to turbulent fluetuations (Bamett and Bentley [1974]).

Considerable effort was made to generate a nearly periodic jet field in the central part of the test section. Pre-design Navier-Stokes analyses indicated that using five jets would provide reasonable periodicity in the three central jets. The near periodicity of the jet field and the planes of symmetry, reduced the amount of data needed to a fourth of the center jet (see Figure 1), Additionally, analy sis of the flow was simplified since the required computational domain size could be reduced. Near periodicity in the central three jets, and the $X-Y$ and $X-z$ symmetres afforded by the geometry were realized, as verified by measurements presented below. Accordingly, relatively high resolution data was taken in a $1 / 4$ jet section at twelve axial locations shown in Figure 2. Scans were taken at all twelve locations. Figure 3 shows a typical cross sectional measurement scan grid. For the first 9 axial sean locations $(x \leq 0.1016 \mathrm{~m})$, a $13 \times 8$ traverse grid was used as shown in Figure 3. Superimposed on this figure are contours of measured axial velocity at $x=0.0279$ min downstream from the confinement inlet. As the jets mixed more thotoughly, well downstream from the inlet ( $x \geq 0.1524 \mathrm{~m})$ ). a coarser traverse grid of $10 \times 5$ was utilized.

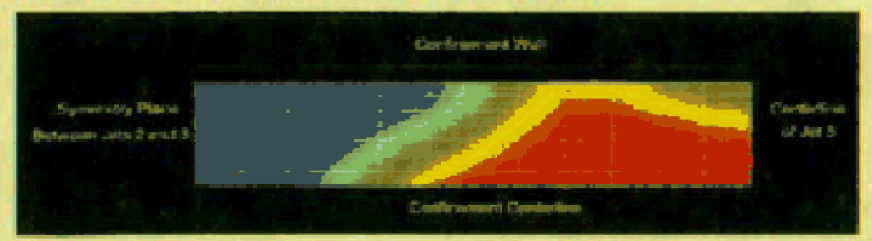

Figure 3. Contours of measured axial velocity $0.0279 \mathrm{~m}$

downstream from confinement inlet, illustrating the crossstream resolution of scans in the measurement space.

\section{Experimental Results and Interpretation \\ Experimental Errors}

LDV measurements are subject to numerous errors, most of which can be quantified. The total uncertainty can be found by combining precision and bias errors as: $\mathrm{U}_{\text {lotal }}= \pm$ $(\mathrm{B}+\mathrm{tP})$, where $\mathrm{B}$ is the bias error, $\mathrm{P}$ is the precision error and $t=1.96$ for a $95 \%$ confidence level (for a sample size greater than 50). Patrick [1987] states that the bias enrors include errors from laser beam geometry, signal processor errors and seoding bias errors. Most of the bias errors are very small compared to precision emors (discussed below) and are thus neglected. The bias errors which can be of the same order of magnitude as the precision crrors are velocity and angle bias, As mentioned above, the velocity bias error is corrected using transit time weighting, while frequency shifting was used to minimize angle bias. Thus the bias errors can be neglected

The precision errors in LDV measurement are data processing errors which result from averaging a finite number of data samples per data point. In LDV measurements, the velocity does not remain constant during the sampling period, but fluctuates due to turbulenee. Thus the precision error in the mean velocity $\left(\mathrm{S}_{\mathrm{V}}\right)$, assuming a normal distribution of velocity samples, is:

$$
\frac{S_{\mathrm{V}}}{\bar{V}}=\frac{1}{\sqrt{\mathrm{N}}}\left(\frac{\mathrm{V}}{\bar{V}}\right) \text {, }
$$

where $\bar{V}$ is the sample mean velocity. $N$ is the sample sire, and $V^{\prime} / V$ is the local intensity. Patterson [1982] states that the mean square turbulence intensity has a Chi-square distribution. For a large sample size $(\mathrm{N}>50)$, the precision error of the turbulence intensity measurement can be found from:

$$
\frac{S_{v^{\prime}}}{v^{\prime}}=\frac{1}{\sqrt{2 N}}
$$

For the LDV measurements taken in this study, 3000 axial and tangential coincident samples were taken at each measurement position. This gives an uncertainty of approximately $\pm 2 \%$ inside the jet, $\pm 4 \%$ in between the jets for both $U$ and $V$ and $\pm 2 \%$ for $\sqrt{U^{\prime} u^{4}}$ and $\sqrt{v^{\prime} v^{\prime}}$ (these errors are based on nomalization with respect to $\mathrm{U}_{\text {bulk }}$ ).

\section{Flow Field Characterization}

Several initial characterization studies of the flow field were performed to verify the absence of large scale unsteady motions, to venify the desirad symmetry and periodicity characteristics of the five jet flows and to characterize the flows well upstream and downstream from the confinement inlet.

Figure 4 a shows an energy spectrum of axial velocity measured at the center of jet 3, 2.67 confinement heights downstream from the confinement inlet $(x=0.0508 \mathrm{~m}, \mathrm{y}=$ $0.0 \mathrm{~m}, z=0.0 \mathrm{~m}$ ). The plot shows a Fast Fourier Transform (FFT) of the 500,000 data points taken at an average random acquisition rate of approximately $525 \mathrm{~Hz}$. For the geometric length and mean velocity seales of the present configuration, a turbulence scale range of approximately $100 \mathrm{~Hz}$ to 10000 $\mathrm{Hz}$ is anticipated. Clearly the spectrum only captures the larger scales of turbulence (the energy content of the smaller scales being aliased to lower frequencies). It exhibits no indication (peak) associated with long time seale quasiunsteadiness associated with the "mean" flow (as may be manifested in jet "flapping"). 


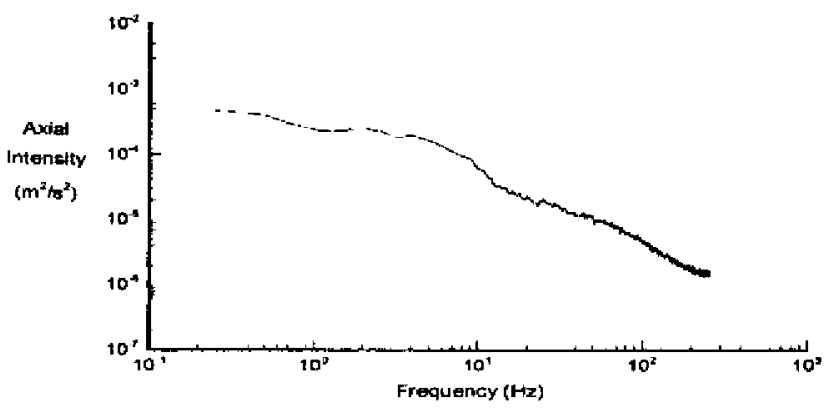

Figure 4a. Energy spectrum of axial velocity taken at $x=.0508 \mathrm{~m}, y=0.0 \mathrm{~m}, z=0.0 \mathrm{~m}$

Several transverse scans ( $\overline{\mathrm{U}}=\mathrm{U} / \mathrm{U}_{\mathrm{ct}}$ vs, y) were taken along the centerline of the confinement $(z=0.0 \mathrm{~m})$. These served to provide guidance to. adjust the flow rate through the outer jets to maximize the periodicity of the center three jets. Figure $4 b$ shows the data from the $x=0.0508 \mathrm{~m}$ scan, and illustrates the near periodicity achieved. The flow rate splits through jets $1-5$, were 19.7,20.2,20.2, 20.2 and $19.7 \%$ respectively of the total test section flow rate of $6.31 \mathrm{xl}^{-3} \mathrm{~m}^{3} / \mathrm{s}$. The axial momentum defect which appears at the centerline of each jet in this plot will be discussed below.

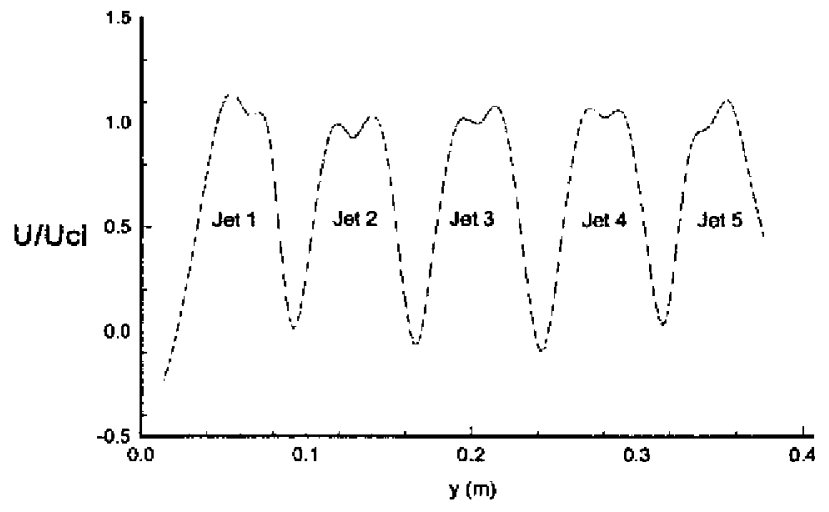

Figure $4 \mathrm{~b}$. Measured axial mean velocity vs. $y$ at $\mathrm{x}=.0508 \mathrm{~m}, \mathrm{z}=0.0 \mathrm{~m}$.

Figure 4c shows the nearly symmetrical scans of $\overline{\mathrm{U}}$ vs. $\mathrm{z}$ along the centerline of jet $3(y=0.2032 \mathrm{~m})$ at $x=0.0508 \mathrm{~m}$ and $x=0.1016 \mathrm{~m}$. Figures $4 \mathrm{~b}$ and $4 \mathrm{c}$ serve to justify the use of the three symmetry planes exploited in the detailed measurement program pursued and in Navier-Stokes analysis (details of CFD computations appear in Kunz et al. [1995]).

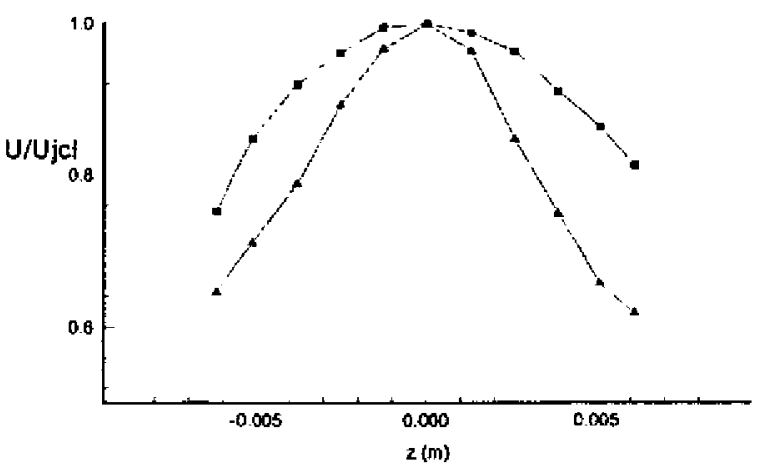

Figure 4c. Measured axial mean velocity vs. $z$ for jet 3 at $y=.2032 \mathrm{~m}$ for $\mathrm{x}=.0508 \mathrm{~m}(\Delta)$ and $.1016 \mathrm{~m}(\boldsymbol{\sigma})$.

As the jets mix, the confinement flow approaches that of a fully developed two-dimensional turbulent duct flow ( $\mathrm{V}, \mathrm{W} \cong 0, \mathrm{U}=\mathrm{U}(\mathrm{z})$ ), since three-dimensional effects become negligible (aspect ratio of confinement $=21.3$ ). A detailed scan was performed in the $z$ direction near the confinement outlet, 34.67 confinement heights downstream from the inlet location $(x=0.6604 \mathrm{~m}, y=0.2032 \mathrm{~m}$ ). Figures $5 a$ and $5 b$ show the measured axial velocity profile vs. $z$ at this location. (Measured transverse velocity was no more than $0.007 \overline{\mathrm{U}}_{\mathrm{cl}}$ ). The open symbols in Figures Sa-c correspond to data obtained very close to the confinement wall ( $\mathrm{z}$ $\left.z_{\text {wall }}=0.12,0.19 \mathrm{~mm}\right)^{1}$. A normalized wall shear stress $\tau_{\mathrm{w}}$ of $\mathrm{C}_{\mathrm{f}} \equiv 2 \tau_{\mathrm{w}} / \rho \mathrm{U}_{\mathrm{cl}}^{2}=0.0065$ collapses the axial velocity reasonably well to a logarithmic law-of-the-wall profile as seen in Figure 5a. (A spline fit through the first two data points yielded $C_{f}=0.0057$ ). Laufer (1950) investigated several nearly fully developed channel flows including two of very similar Reynolds numbers to the PCJ configuration $\left(\mathrm{R}_{\mathrm{e}}^{*}=24400,24600\right.$ vs. 23400 for PC. $)$. Laufer reported wall stress values of $C_{f}=0.0036$ and 0.0038 for these two channels, significantly lower than the values deduced for the PCJ configuration. Consideration of this difference and of the mean velocity and turbulence intensity data in Figures $5 b$ and 5c suggest that the Reynolds nomal and shear stresses in the PCJ confinement flow are significantly higher than in Laufer's channels. This is consistent with results which indicate that the turbulence levels in the PCJ configuration are still decaying from their large near-inlet values at this nearoutlet location

Figure 6 shows a plot of measured axial mean velocity in the inlet pipe to jet $3,1.75$ pipe diameters upstream of the confinement inlet $(x=-0.0667 \mathrm{~m})$. The profile is seen to be nearly symmetric, and compares well with a $1 / 7$ power law distribution. Some evidence of the approaching confinement area step change is discemible in slight symmetric inflections near $\mathrm{z}= \pm 0.01 \mathrm{~m}(\mathrm{z} / \mathrm{h} \cong \pm 0.5)$

1. The measurement volume length of $0.32 \mathrm{~mm}$ in water indicates that the probe volume partially intersects the wall for these two measurement locations. Though the measured values of mean velocity appear reasonable, the normal stresses appear to be unrealistically high (especially $\mathbf{v}^{\prime} v^{\prime}$ ) Accordingly, the uncertainty associated with these two points was deemed significantly higher than the uncertainty estimated below for all the other top scan data. 
a)

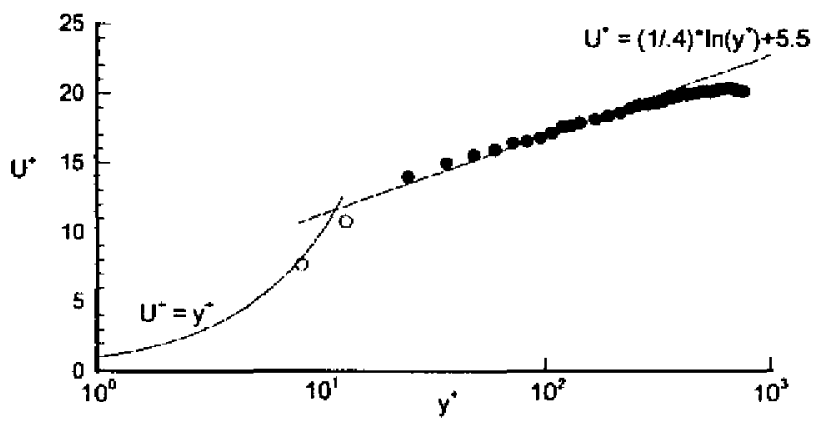

b)

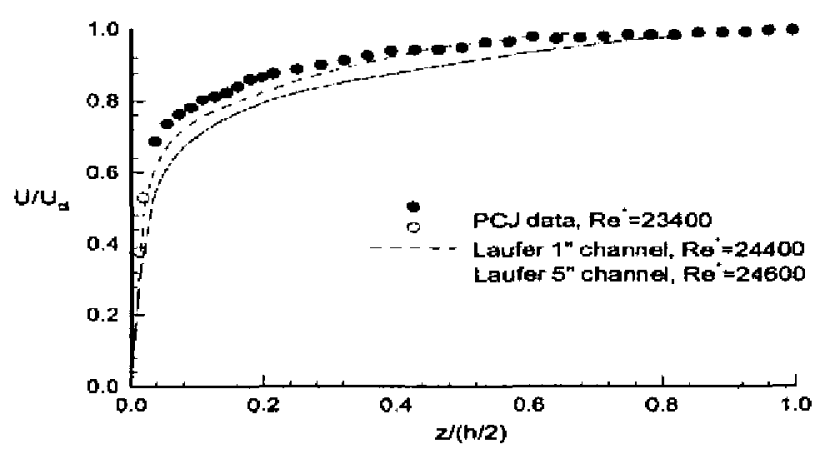

c)

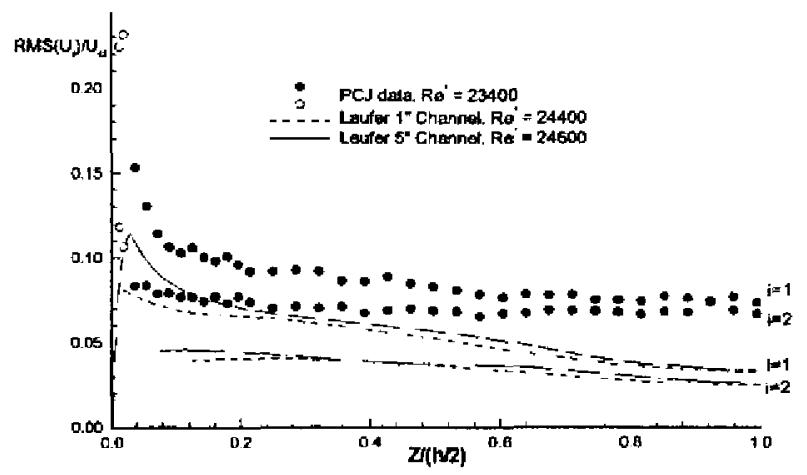

Figure 5. Measurements of axial velocity and normal stresses vs. $z$ at $x=0.6604 \mathrm{~m}, y=0.2032 \mathrm{~m}$. a) Comparison of axial velocity with law-of-the-wall. b) Comparison of axial velocity with data due to Laufer [1 950]. c) Comparison of normal stresses $\mathbf{u}^{\prime} u^{\prime}(i=1)$ and $\bar{v}^{\prime} v^{\prime}(i=2)$ with data due to Laufer [1950].

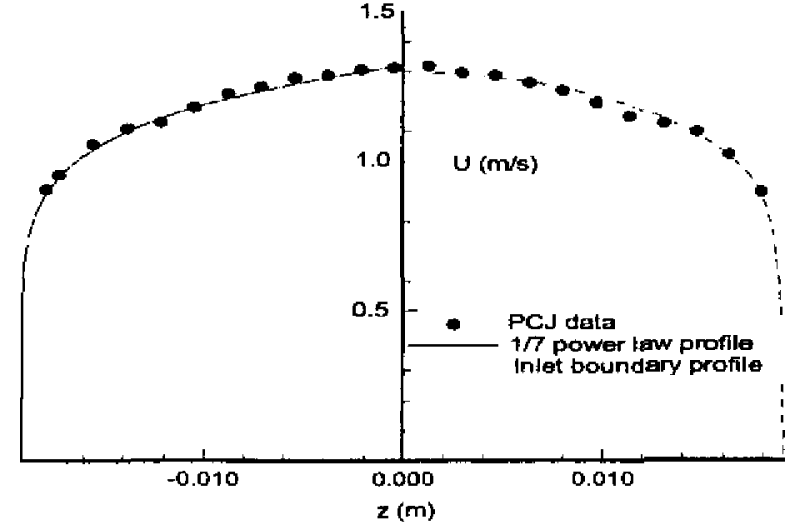

Figure 6. Comparison of measured axial mean velocity in the jet 3 inlet pipe at $x=-0.0667 \mathrm{~m}$, with $1 / 7$ power law profile.

\section{Detailed Seans}

Figures 7 and 8 present axial and transverse mean velocity data at the first 10 scan locations. Figures $7 \mathrm{a}-\mathrm{j}$ show front view contour plots of $U$ and V, Figure 7k shows a plot of the $x=0.0381 \mathrm{~m}$ scan. Clearly, the data are quite smooth, and both mean velocity components were found to be repeatable to within $0.02 \mathrm{~m} / \mathrm{s}$. Several important features of the mean flow are obtained from the data in Figure 7.

Flow issuing into the confinement from the inlet pipe encounters a variable height "forward step" contraction, the maximum height of which occurs at the pipe/jet centerline. This gives rise to a large axial momentum defect at the jet centerlines. This defect is observed only very near the confinement wall at $x=0.0051$ (Figure 7a). The size of this defect region grows in $\mathrm{z}$ and $\mathrm{y}$ over the first several scan locations. This is due in part to turbulence diffusion. Secondary flows which develop near the inlet likely also play a role in this transport of low momentum fluid. The peak jet centerline velocity is seen to increase due to this blockage (see also Figure 8). The region of diminished axial velocity reaches the confinement centerline at $x=0,0270 \mathrm{~m}$ (Figure $7 \mathrm{~d}$ ). This may be considered the axial extent of the near potential flow core at the jet centerline. This centerline defect is observed all across the confinement from $\mathrm{x}=0.0270 \mathrm{~m}$ to $\mathrm{x} \cong 0.15 \mathrm{~m}$ (Figure 7j) where its influence is seen to wash out.

As the parallel jets issue into the confinement, a large recirculation appears between adjacent jets. This recirculation zone is seen to be wider $(\Delta y)$ and longer $(\Delta x)$ near the confinement wall than at the corffinement centerline (Figures $7 \mathrm{a}-\mathrm{g})$. Specifically, at the confinement centerline, $x_{\text {Teattach }} \cong$ $0.063 \mathrm{~m}$, compared to $\mathrm{x}_{\text {reatt }} \cong 0.069 \mathrm{~m}$ at the scan location closest to the wall $(\mathrm{z} /(\mathrm{h} / 2)=0.859)$. Maximum magnitudes of reversed flow velocities are larger near the confinement wall than at the confinement centerline: $|\nabla|_{\text {max,recirc }} \cong$ $0.67 \mathrm{~m} / \mathrm{s}$ vs. $0.51 \mathrm{~m} / \mathrm{s}$.

Downstream from the recirculation zones between the jets $(x>0.07 \mathrm{~m})$ significant negative $V$ velocities were measured across the jet due to jet spreading (strearnline divergence). Near the confinement inlet $(x=0.0127,0.0216$, $0.0270,0.0381$ ), however, relatively large transverse velocities near the wall are positive (towards jet centerline) and near the confinement centerline negative. The magnitudes of 

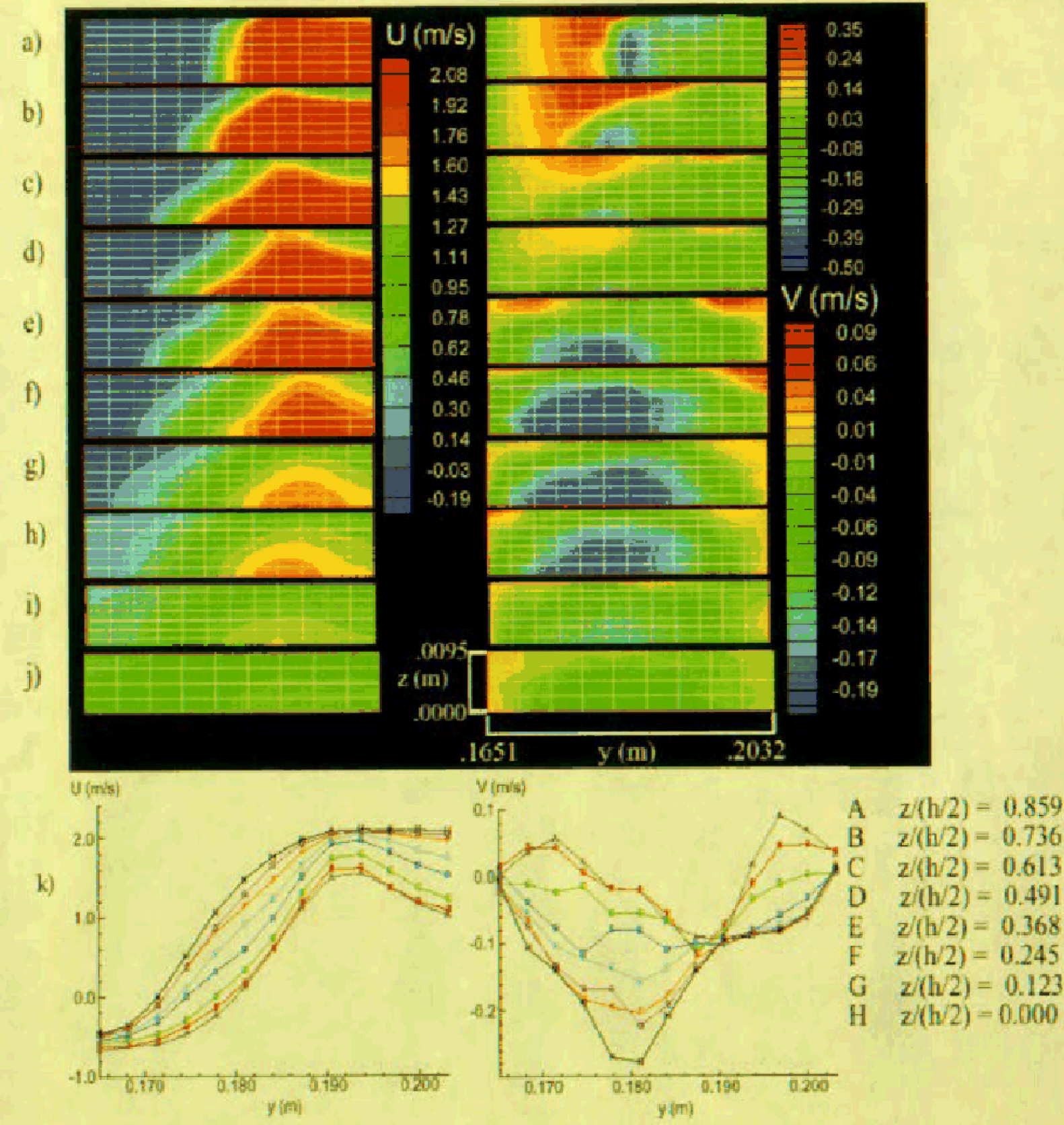

Figure 7. Measured mean velocities, $\mathrm{U}$ and $\mathrm{V}$. a) - j) are contour plots at $\mathrm{x}=0.0051,0.0127,0.0216,0.0270$ $0.0381,0.0508,0.0635,0.0762,0.1016,0.1524 \mathrm{~m}$ respectively. Expenimental scan location quid is overlaid on contour plots. Two contour level bars for $V$ velocity correspond to top four and botiom six scans respectuvely. Figure 3 shows relative position of confinement wall and symmetry planes for these plots. k) shows cappet plots of these data at $x=0,0381 \mathrm{~m}$ 


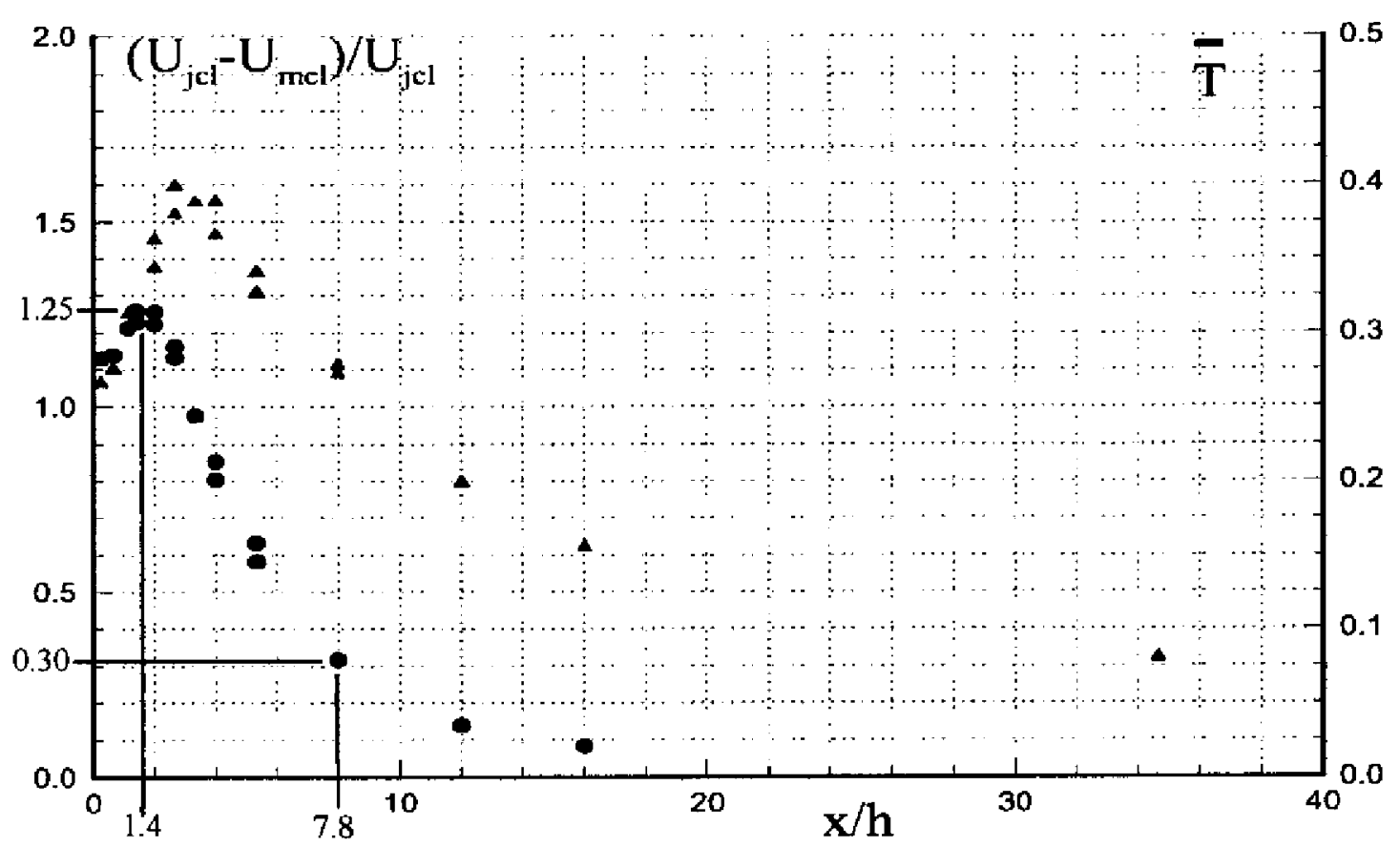

Figure 8. Measured axial distributions of jet 3 axial velocity decay (6)and mass weighted average axial turbulence intensity(). 
these transverse velocities reach nearly $0.4 \mathrm{~m} / \mathrm{s}$, compared to the cross-section bulk velocity of $0.82 \mathrm{~m} / \mathrm{s}$. This suggests significant streamwise vorticity, arising from streamline divergence and secondary flows. Transverse velocities eventually diminish towards zero as the jets decay.

In Figure 8, the axial jet decay along the confinement centerline is presented as a plot of normalized difference between measured axial velocity at the jet 3 centerline $\left(y_{\text {jcl }}=\right.$ $0.2032 \mathrm{~m}$ ) and at the symmetry plane between jets 2 and 3 $\left(\mathrm{y}_{\mathrm{mcl}}=0.1651 \mathrm{~m}\right.$ ). (Two velocity difference values appear at several axial locations since repeated measurements were performed there.) The difference between $U_{i c l}$ and $U_{\text {mel }}$ increases near the inlet as discussed above, reaching a maximum of $\left(\mathrm{U}_{\mathrm{jcl}}-\mathrm{U}_{\mathrm{mcl}}\right) / \mathrm{U}_{\mathrm{jcl}} \cong 1.25$ at $\mathrm{x}=0.027 \mathrm{~m}(\mathrm{x} / \mathrm{h}=1.4)$. The jets then mix out quite rapidly, falling to $\left(U_{j e l}-U_{m c}\right) /$ $\mathrm{U}_{\mathrm{jcl}} \cong 0.3$ at $\mathrm{x}=0.152 \mathrm{~m}(\mathrm{x} / \mathrm{h}=7.8)$.

Also presented in Figure 8 is mass weighted average axial turbulence intensity, defined as:

$$
\overline{\mathrm{T}}=\frac{1}{\mathrm{U}_{\mathrm{bulk}}} \sqrt{\int_{\mathrm{A}_{\mathrm{xs} 1 / 4}} \overline{\mathrm{uu}} \mathrm{UdA}_{\mathrm{xs} 1 / 4} / \int_{\mathrm{A}_{\mathrm{xs} / 4}} \mathrm{UdA}_{\mathrm{xs} 1 / 4}}
$$

plotted vs. $x$. This intensity is seen to increase rapidly near the inlet, reaching approximately 0.40 at $x=0.0508 \mathrm{~m}$. The turbulence intensity then decays exponentially. At $\mathrm{x}=$ $0.6604 \mathrm{~m}$ the average turbulence intensity is approximately 0.08 , and still apparently decaying (see Figure $5 \mathrm{c}$ and discussion).

Figure 9 shows selected comparisons of measured axial and transverse turbulence intensities at three axial locations. The three selected scans are located: a) very near the confinement inlet $(x=0.0051 \mathrm{~m})$, b) approximately halfway along the axial extent of the recirculation zones $(x=0.027 \mathrm{~m})$ and c) approximately two confinement heights downstream of reattachment $(x=0.1016 \mathrm{~m})$. Very near the confinement inlet, turbulence intensities are quite small except near the wall and at the interface between the incoming jet and the recirculation region between jets, where maximum local intensities, $\sqrt{\overline{u^{\prime} u^{\prime}}} / \mathrm{U}_{\text {local }}$, of approximately $25 \%$ are observed. At $x=0.027 \mathrm{~m}$, intensities grow quite large in the vicinity of the jet-recirculation zone interface. The location of peak intensity shifts towards the jet centerline as the confinement wall is approached, consistent with the cross-sectional shape of the inlet (Figure 1). Turbulence levels at the confinement centerline remain smatl near the jet centerline, since flow at this location has primarily been subject to relatively small normal strains.

Transverse intensities exhibit the same trends as axial intensities at these first two scan locations, though the magnitudes of $\mathrm{u}^{\prime} \mathrm{u}^{\prime}$ are nominally $50 \%$ higher. Downstream of reattachment, $\overline{u^{\prime} u^{\prime}}$ and $v^{\prime} v^{\prime}$ exhibit significantly different character. Specifically, in the defect region between the jets $v^{\prime} v^{\prime}$ is larger than $u^{\prime} u^{\prime}$, and diminishes monotonically toward the jet centerline. $u^{\prime} u^{\prime}$ retains its upstream character of maximum magnitude near the location of maximum transverse shear $(\partial \mathrm{U} / \partial \mathrm{y})$.

The Reynolds shear stress data, $\overline{u^{\prime} v^{\prime}}$, are plotted in Figure 10 at the same three representative axial locations. Qualitatively, these shear stresses follow gradient diffusion trends, as comparison with Figure 7 affirms.

\section{Conclusions}

Detailed LDV measurements were taken in a parallel confined jet configuration. Two components of mean veloc- ity and three Rey nolds stresses were obtained. Several conclusions were drawn from the measurements:

Test section design and tuning the flow rates in the outermost jets gave rise to a nearly periodic flow that was exploited along with planes of symmetry in the measurement program. This also, of course, facilitates Navier-Stokes analysis efforts.

Detailed resolution of the development of quantities obtained from the measurements provided insight into the complex mean flow and turbulence physics of this flow.

Mean flow measurements characterized important features including rapid jet decay, large recirculation zones between jets, strong secondary motions and peak axial velocities away from the jet centerline.

Turbulence intensities near the confinement inlet are quite high due to abrupt geometry change and dump diffusion there.

Significant anisotropies in the axial and transverse intensities appear near the midpoint between adjacent jets. This persists well downstrean. The Reynolds shear stresses were observed to qualitatively follow gradient diffusion trends.

\section{References}

Bamett, D, Bentey, H., 1974, "Statistical Biasing of Individual Realization Laser Velocimeters," Proceedings of the Second Intermational Workshop on Laser Velocimetry, Purdue University, p. 428.

Davis, M.R., Winarto, H., 1980, "Jet Diffusion From a Circular Nozzle Above a Solid Plane," Journal of Fluid Mechanics, Volume 101, Part 1, p. 201.

Holdeman, J.D., Foss, J.F., 1975, "The Intiation, Development, and Decay of the Secondary Flow in a Bounded Jet," ASME Journal of Fluids Engineering, September, p. 342 .

Krothapalli, A. Baganoff, D., Karamcheti, K., 1981, "Partially Confined Multiple Jet Mixing," AIAA Journal Vol. 19, No. 3., p. 324

Kunz, R.F., D'Amico, S.W., Vassallo, P.F., Zaccaria, M.A., Aksoy, H., So, R.M.C., 1995, "LDV Measurement and Navier-Stokes Computation of Parallel Jet Mixing in a Rectangular Confinement," AIAA Paper 95-2147.

Laufer, J, 1950, "Investigation of Turbulent Flow in a Two-Dinensional Channel," NACA Report 1053, p. 1247

Launder, B.E., Rodi, W., 1983, "The Turbulent Wall Jet - Measurements and Modelling, Annual Review of Fluid Mechanics, Vol. 15, p. 429.

Newman, B. G., Patel, R. P., Savage, S. B., Tjio, H. K.,

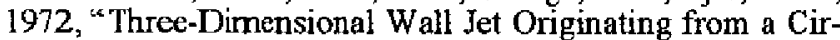
cular Orifice," Aeronautical Quarterly, Vol. 23, p. 188.

Patrick, R. W., 1987, "Flowfield Measurements in a Separated and Reattached Flat Plate Turbulent Boundary Layer," NASA CR-4052, March.

Patterson, R. W., 1982, "Turbofan Forced Mixer-Nozzle Internal Flowfield, I-Benchmark Experimental Study," NASA CR-3492, April. 

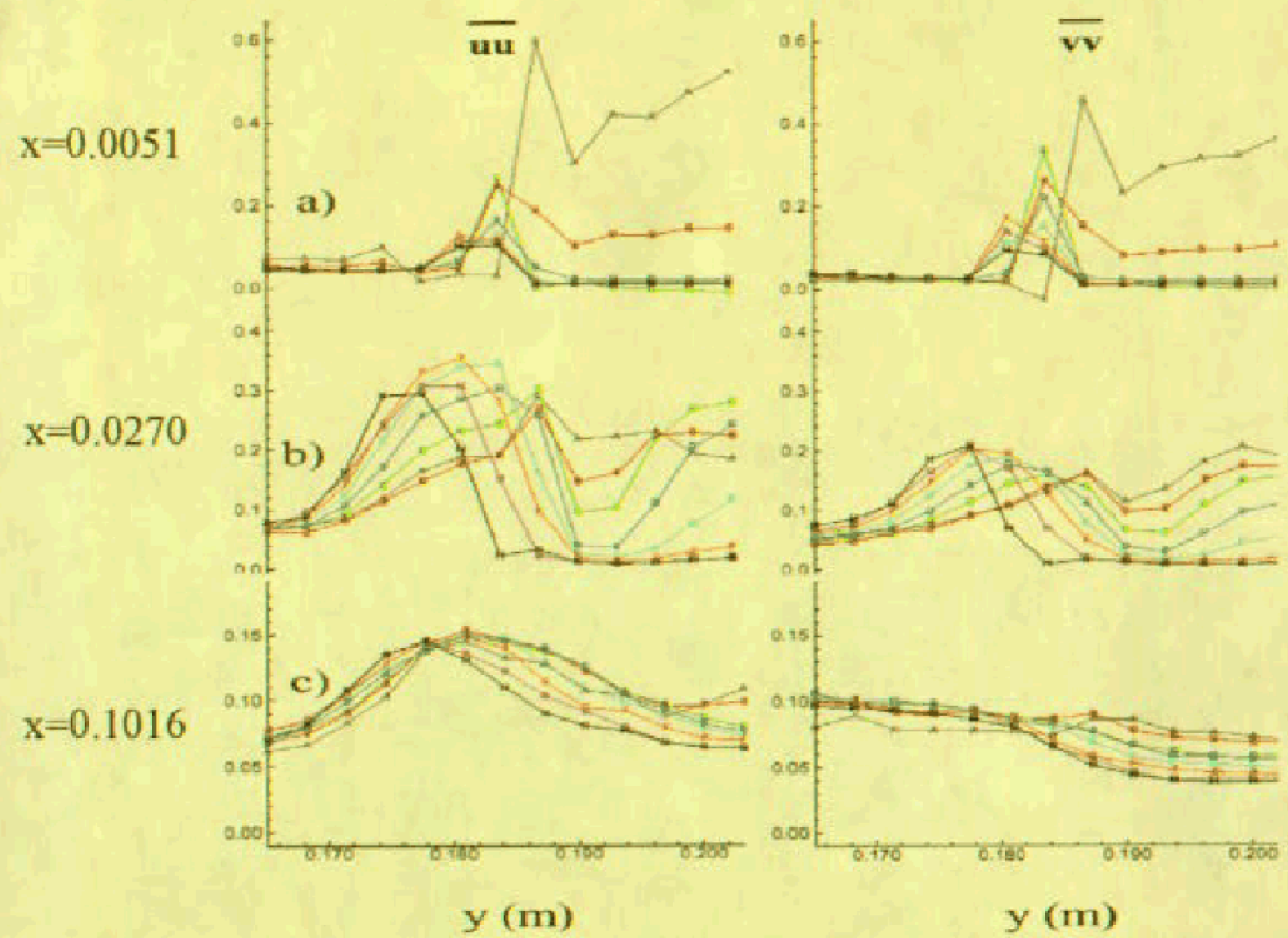

Figure 9.

Cappet plots of measured axial and transverse intensities $\left(\mathrm{m}^{2} / \mathrm{s}^{2}\right)$. Left columa: $\overline{u^{\prime} \mathrm{u}^{\prime}}$, right column: $\overline{v^{\prime} v^{\prime}}$. a) - c) at $x=0.0051,0.0270,0.1016$ m. Refer to Figure 7 for key.

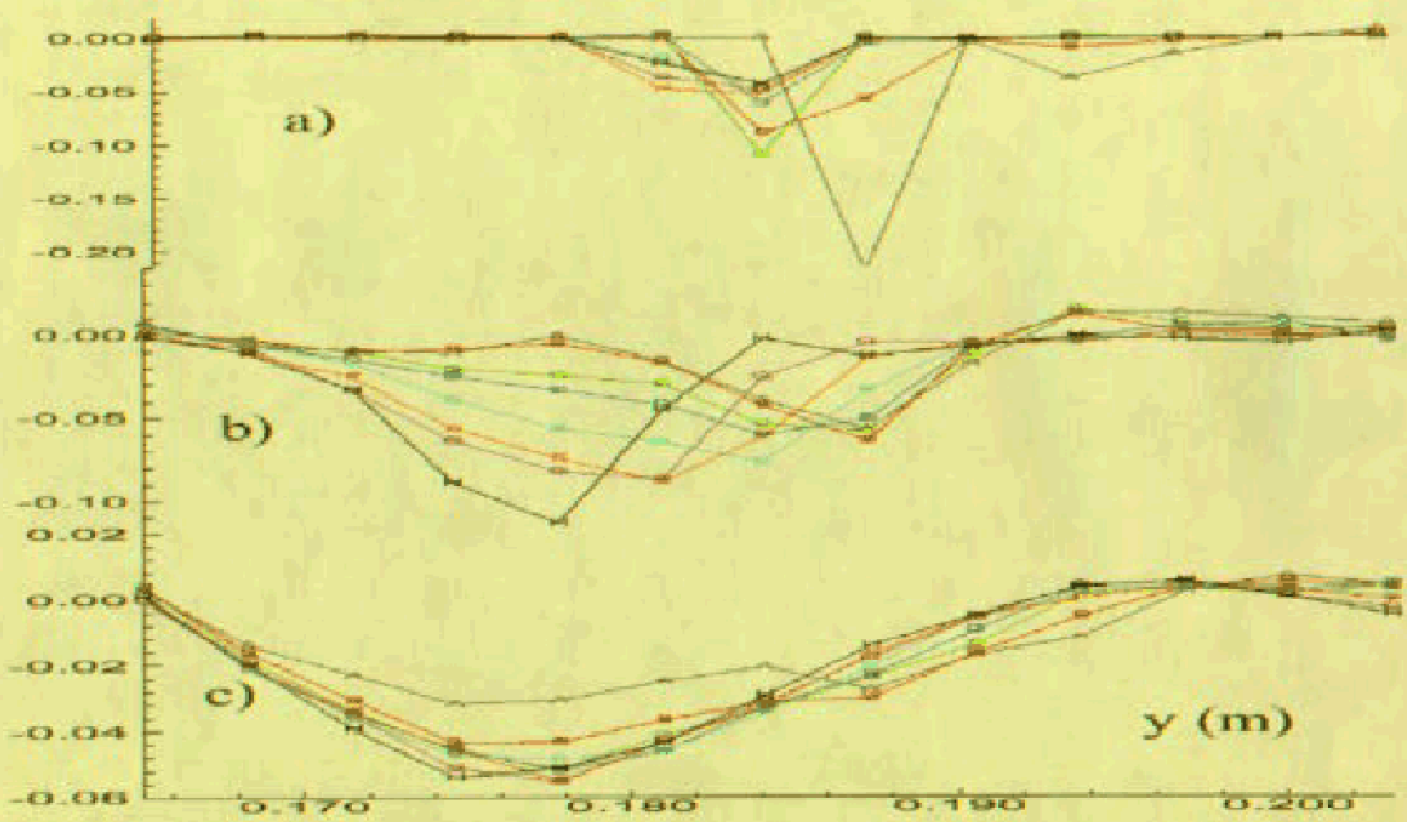

Figure 10. Carpet plots of measured Reynolds stress, $\overline{u^{7} v^{7}}\left(\mathrm{~m}^{2} / \mathrm{s}^{2}\right)$ a) - c) at $\mathrm{x}=0.0051,0.0270,0.1016 \mathrm{~m}$ Refer to Figure 7 for key. 